\title{
Discipline Formation in Information Management: Case Study of Scientific and Technological Information Services
}

\author{
Michael Middleton \\ QUT School of Information Systems, Brisbane, Australia
}

\author{
m.middleton@qut.edu.au
}

\begin{abstract}
Discipline formation in information management is investigated through a case study of the origination and development of information services for scientific and technical information in Australia. Particular reference is made to a case of AESIS, a national geoscience, minerals and petroleum reference database coordinated by the Australian Mineral Foundation. This study provided a model for consideration of similar services and their contribution to the discipline. The perspective adopted is to consider information management at operational, analytical and strategic levels. Political and financial influences are considered along with analysis of scope, performance and quality control. Factors that influenced the creation, transitions, and abeyance of the service are examined, and some conclusions are drawn about an information management discipline being exemplified by such services.
\end{abstract}

Keywords: Discipline formation, Information services, Information management, Australia, Scientific information, Bibliographic databases

\section{Introduction}

Discipline formation is a study of interest to academics who seek to define the boundaries of their fields of endeavor. This is so that effective contextualization can take place for study of a field by means of models for representing shared concepts; coherent expression being given to research programs; commonly accepted methods of investigation; and employing principles and values about which there is concurrence within a professional community.

Analysis of discipline formation in information studies has taken various forms. These range from investigation of the overlapping concerns of professional associations though to compilations of seminal papers, which provide underpinning principles. However, most examination is of conceptual boundaries. Articulation of what comprises the discipline varies considerably according to the perspective, training and context of who is expressing it. So there are disparities between information science, information systems, information management, knowledge management, library science and the like. These are explored briefly in the following section as a preamble to a historical study of the initiation of an

Material published as part of this journal, either on-line or in print, is copyrighted by Informing Science. Permission to make digital or paper copy of part or all of these works for personal or classroom use is granted without fee provided that the copies are not made or distributed for profit or commercial advantage AND that copies 1) bear this notice in full and 2) give the full citation on the first page. It is permissible to abstract these works so long as credit is given. To copy in all other cases or to republish or to post on a server or to redistribute to lists requires specific permission from the publisher at Publisher@InformingScience.org application of information management in Australia.

This study is being undertaken both as an investigation of discipline formation per medium of utilization of principles in a nascent profession, and to provide a historical record of the development of a particular type of in- 
formation service - that which deals with scientific and technical information (STI). This paper reports on one case as a model for several other cases on genesis and development of Australian STI services. These studies in turn form part of a wider study of discipline formation in information management. A research question is therefore: does the provision of STI services provide an effective exemplar for the discipline of information management?

The study is undertaken using a protocol that considers the services as information management applications. These applications are analyzed in terms of overlapping administrative, analytical and operational domains. This domain approach was expressed by Diener (1992), and used to organize a book illustrating principles and practice of information management (Middleton, 2002). The discipline as expressed in the book forms the basis of the case study protocol.

The development of STI services in Australia was stimulated during the 1960s by several factors. These included improved mechanisms for information dissemination, and developments in information policy. However, in some respects progress was achieved in spite of policy frameworks and the lack of coordination between the lead institutions that established and provided the services.

Most STI services developed in Australia were initiated in the 1970s accompanied by concerns about the proportion of national material that was not appearing in international databases, a growing desire to address public policy concerns about provision of information, and establishment through information technology of the technical capacity to provide such services. A review of these influences has been presented by Middleton (2004).

This study is confined to an analysis of one service, the Australian Earth Sciences Information Service (AESIS), but makes some reference to a number of other services being developed at the time. The initial investigation is based upon operational experience with several services along with a literature and database review, and interviews. It therefore provides a descriptive history of one such service, along with commentary on the factors contributing to its establishment, and development in the light of other STI services.

\section{Disciplinary Study of Information Management}

There have been many years of debate on what comprises the defining knowledge of the field of information science. Several works have provided overviews and debate about disciplinary boundaries. Examples are the early compilation by Saracevic (1970) and more recent accounts by Norton (2000) and Griffiths (2000).

It is to be expected that this debate would encompass the application of information science in areas such as information systems and information management, which themselves are spoken of as disciplines. However there seem to be professional, research and conceptual barriers that inhibit such an inclusive approach across the fields.

Contributing to these restraints are a lack of dialogue between information science and information systems researchers, and a lack of conceptual reinforcement of information management applications by theoretical constructs and principles of information science.

In the case of lack of dialogue, this has been characterized as an apparent disjunction between the research of information science and information systems For example, Ellis, Allen, and Wilson (1999) considered the subfields of user studies and information retrieval, which are of interest to both fields. Using citation analysis, they found almost no overlap in relation to the disciplinary fields of the most highly cited authors. They attributed this to the nature of scientific disciplines, the socialization process of researchers in the different fields, and to institutional pressures. 
This disjunction seems to persist in more recent analysis of discipline formation being undertaken in the respective fields. For example Webber (2003) reviewing the status of information science as a discipline in the UK, makes little reference to studies in information systems or examination of an information systems/information science boundary. She examines definitions that relate to investigation of information properties and behavior, forces that govern its flow and use and techniques for improve representation, organization, storage, retrieval and dissemination.

On the other side of the coin, the information systems academy also continues to question whether information systems is a discipline. For example Khazanchi and Munkvold (2000) look for disciplinary aspects, and they consider both information systems and information science. However they differentiate them, seeing information science as a secondary reference discipline of information systems. Their purview of information systems has it being an investigation of effective use of information and the potential impact of software systems and enabling information technologies on the human, organizational, and social world. They maintain that although IT is the key enabling technology for both information science and information systems, the focus of information science is different in that it is on the structure and management of large information entities, with documentalists and librarians being key agents.

Although they pay attention to information science, they do not consider such elements as definitions of information or exploration of tenets and principles of information science, and how these may inform work in information systems as an application. With information systems study the emphasis seems to be substantially on the systems and process; with information science the emphasis seems to be substantially on the information and its content. They have in common an emphasis on social context and use, but this has not brought unity of focus. Despite this, there seems to be agreement in both fields about their essential interdisciplinarity.

The second point made earlier was about lack of conceptual reinforcement between the science of information and its application through management. It is only relatively recently that scholars have spoken in terms of formation of an information management discipline. It remains problematical to do so since there are many contributing disciplines, and it is difficult to identify a core that is accepted by all adherents.

Nevertheless, there have been attempts to characterize information management by considering how information science principles are applied in practice. For example, writers such as Rowley $(1998,1999)$ have paid some attention to categorizing the practice of principles articulated within information science.

A recent survey of the area (Wilson, 2003) says that if information management is to have a viable role in organizational performance, then the function (rather than the idea) must become accepted as a key part of organizational structures, and be accompanied by coherent educational curriculum and a research agenda.

It seems that an agreed disciplinary paradigm is yet to be accepted. Further, discipline formation investigations seem to focus more on information science research without much reference to what is engaged in by practicing information professionals.

Information management is often described as interdisciplinary or multidisciplinary. It has yet to settle upon carefully developed methodologies that have assured disciplinary integrity and success. However there are a significant number of information professionals who believe they are carrying out something called information management, as evidenced by the many professional associations that have been formed using variations on the name information management.

Studies of what information professionals do have been many and varied since Bell's "postindustrial society" motivated such investigation. For example, a seminal study that detailed the work of the information professions in the USA was that of Debons, King, Mansfield, and Shirey (1981). 
Their broad categories for information work included: managing information operations, programs, services, or databases; information systems analysis; analyzing data and information on behalf of others; preparing data and information for use by others; searching for data and information on behalf of others; and information systems design.

Abbott (1988) has conducted sociological analysis of the division of expert labor, and how the professions work. He concentrates on the way that professional tasks are delineated, and stratified. His work includes case studies of three professional areas, one of which is the information professions. He sees these as qualitative (principally librarians and journalists), and quantitative (a "complex and contentious group" including accountants, statisticians, operations researchers, and the like). He envisaged these groups coalescing under one jurisdiction stimulated by the joint catalysts of computing technology and of information science.

Many subsequent studies have commented upon the diffuseness of the employment sector for such work. Cronin, Stiffler and Day (1993) saw it in terms of the 'heartland' (traditional jobs in established institutions), the 'hinterland' (information work utilizing traditional skills, but outside the traditional institutions, or requiring adaptation), and the 'horizon' (software engineers, telecommunications managers, and the like).

The periodicals of the professional information associations often examine the boundaries of the field, and what employment in it means. For example in Online, Corcoran, Dagar and Stratigos (2000) report excerpts from their Outsell Inc study and provide a wealth of data on roles. The most predominant are information research; selection, evaluation and acquisition of external content sources; training and educating end-users; developing and managing overall content solutions for users; managing desktop deployment of external content; performing value-added information analysis; and managing internally generated content.

The research reported in this paper attempts to extend the examination of discipline formation by consideration of how information science principles have been applied in the context of managing STI services. In this respect therefore, information management is defined as application of information science. It is the application of policy, analysis, and principles to techniques for improving representation, organization, storage, retrieval and dissemination of information.

\section{Research Method}

A descriptive case study methodology (Yin, 2003) is applied in which the unit of analysis is a system of action, in this situation, the establishment and maintenance of a service, applied over multiple cases.

The protocol comprises:

- Project objectives that include:

- Provision of an overview of development of STI services in Australia;

- Extension of this overview through detailed investigation to take account of public policy influences and corporate imperatives;

- Testing the utility of a case study procedure derived from description of discipline formation.

- Collection of information via a combination of approaches requiring examination of published and archival documentation, for which access has been provided, and the interviewing of key figures who were involved in the creation of the national services. 
- Case study questions structured according to the context of a recently written book on information management (Middleton, 2002). In each case the STI service is to be examined from three information management viewpoints described in detail in the publication, and briefly as:

- Operational aspects referring to the different tasks carried out during staged processes of information handling, for example the creation; distribution; organization (including provision of metadata for information medium and content); retrieval; navigation processes for interaction; presentation; and if necessary disposal or retirement of information;

- Analytical aspects referring to user needs and systems analysis; information resources analysis including audits and assessing information worth; and evaluation procedures;

- Administrative aspects referring to policy and planning aspects and strategic approaches in general.

An example of how analytical and operational factors have been investigated to provide some general guidance for database production is provided by Judge (in Judge \& Gerrie, 1986, p.102). This is derived from a survey of about 40 database producers in Australia of which about half responded. Some examples of their modal (most frequent) answers are shown in Table 1.

The analytical approach as defined for the protocol may be applied to information users as well as to the information sources that they use. For example, this has been carried out in relation to Australian STI services in general by Maguire, Weir \& Wood (1987). They interviewed 117 people including research scientists from the Commonwealth Scientific and Industrial Research Organization (CSIRO), academic scientists from universities, and technical managers drawn from different industry categories. They determined that unsatisfied information needs were found to be greater within the technical managers group, particular with respect to business intelligence. All groups expressed need for greater and more wide ranging database access.

Table 1: Database in formation management (adapted from Judge \& Gerrie, 1986)

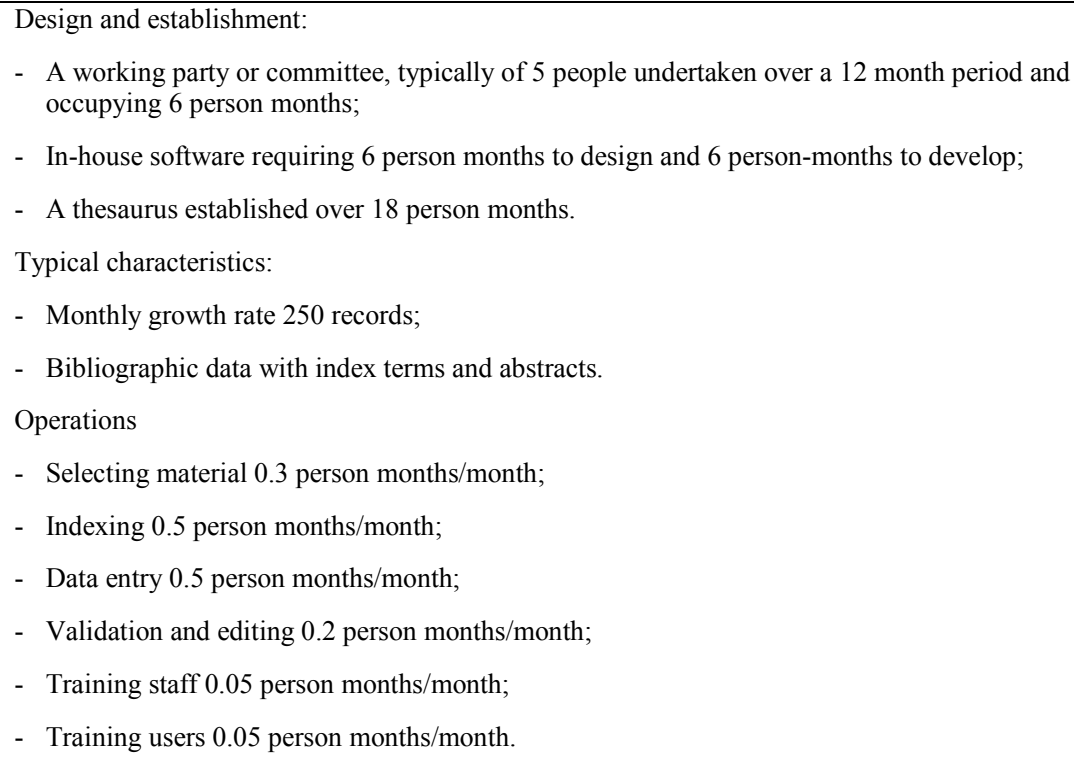


Examples of user needs identification of STI in Australia described from the perspective of individual professionals rather than as research studies have been undertaken in a number of forums. For example both Lay and Thomas (Lane, 1984) provide an engineering viewpoint.

\section{STI Policy}

This brief overview of relevant public policy initiatives is given because of their influence on the strategic aspects of information management within the administrative domain of the case study following.

Drives to establish national information policy in Australia have begun and faltered several times. For a time in the 1970s, STI services were a main focus of information policy. A major attempt to identify requirements and articulate direction was undertaken through the Scientific and Technological Information Services Enquiry Committee. STISEC had been established by the federal government and appointed by the National Library of Australia (NLA) to report on STI services. It recommended both the development of a national information policy, and a national central STI authority to act as focus for activities and promote their orderly development (Australia. Scientific and Technological Information Services Enquiry Committee, 1973-75).

A survey to inform the Committee was conducted based upon random sampling of scientists from a wide range of professional groups. About 2000 responses were received, and findings showed that significant numbers lacked ready access to primary literature, and very few were receiving formal current awareness services.

CSIRO, although forming to some extent a distributed national science library, was reluctant to take on a greater resource provision role without dramatic provision of additional resources. Following the STISEC report however, it was active in collaboration with other agencies in the development of databases. One of these agencies was the NLA which had created the Australian National Scientific and Technological Library (ANSTEL) as one of three 'national libraries' (the others being for social sciences and the humanities), to function within NLA.

ANSTEL embodied such schemes as an Australian industry network that was initiated, among other things, in order to produce current awareness bulletins in STI, and an industry reports database (National Library of Australia, 1977). Unfortunately the NLA was unable to communicate the objectives of services such as this in a way that engaged the wider information services community within which it was seen to operate. Moreover, it could not obtain enough resources for its 'libraries within a library' to pursue its objectives, or to keep them viable.

All the same, NLA was able to point to developments under the umbrella of ANSTEL that had in fact already been embarked upon. For example, there were from 1970 the MEDLARS and subsequent MEDLINE services in association with the U.S. National Library of Medicine, and the Australian Department of Health. There was also the Canadian CAN/SDI software to provide current awareness services from BIOSIS and ERIC databases.

Nevertheless there remained disquiet about what was perceived to be the lack of authority (Swan in Peguero, 1983, p.147). However, the then ANSTEL director suggested that if a national database policy were needed then it would be necessary to demonstrate the failings of present services, and suggest alternative mechanisms. He thought this was unnecessary as ad hoc development had resulted in worthwhile achievements (Yates in Peguero, 1983, p. 30).

Outside CSIRO and NLA, little was done to foster coordinated STI services development. Despite this, ad hoc development resulted in extensive services based upon international databases, complemented by the production of local databases. 
For the purposes of this paper, analysis is confined to one service, AESIS. A summary of its characteristics compared with two of the other services being examined is shown in Table 2.

Data of this type were compiled for a period during the 1980s by the Australian Database Development Association (Quinn, 1988).

\section{Table 2: Australian STI databases}

\begin{tabular}{|c|c|c|c|}
\hline & AESIS & AMI (includes HEAPS) & ENGINE \\
\hline Commenced & 1976 & 1983 & 1982 \\
\hline Creators & Australian Mineral Foundation & NLA & Inst. of Engineers, Australia \\
\hline Subject matter & Earth sciences & Health \& medicine & Engineering \\
\hline Coverage & $(1907-) 1975-2001$ & 1968 & 1980 \\
\hline Annual size & $\sim 4,000$ & $\sim 2,000$ & No \\
\hline Overseas material & About Australia 1979 - & $\begin{array}{l}\text { About Australia; by Austra- } \\
\text { lians }\end{array}$ & $\sim 1300$ \\
\hline $\begin{array}{l}\text { Types of docu- } \\
\text { ments }\end{array}$ & BCDJMRrTS & BCJPRV & BCGJNRT \\
\hline Vendors & $\begin{array}{l}\text { Ausinet } \\
\text { CLIRS } \\
\text { Informit } \\
\text { AMF }\end{array}$ & $\begin{array}{l}\text { Aust Medline network } \\
\text { Informit }\end{array}$ & $\begin{array}{l}\text { Australis } \\
\text { Informit }\end{array}$ \\
\hline International ties & No & Some Medline overlap 2001- & No \\
\hline $\begin{array}{l}\text { Vocabulary con- } \\
\text { trol }\end{array}$ & $\begin{array}{l}\text { Australian geoscience, miner- } \\
\text { als and petroleum thesaurus }\end{array}$ & $M e S H$ & $\begin{array}{l}\text { SHE: subject Headings for } \\
\text { Engineering - 1993; Ei } 1993 \\
\text { - }\end{array}$ \\
\hline Current awareness & $\begin{array}{l}\text { AESIS quarterly } \\
\text { AESIS special lists }\end{array}$ & Tailored searches & No \\
\hline Other outputs & $\begin{array}{l}\text { AESIS cumulation - fiche } \\
\text { Retrospective list series }\end{array}$ & Bibliographies & No \\
\hline Full text & No & Meditext link 1996- & No \\
\hline
\end{tabular}

A Audio recordings
B Books
b Book reviews
C Conference papers
D Digital data \& software
G Government papers

A Audio recordings

\section{Key for types of documents}

$\begin{array}{llcl}\text { J } & \text { Journal articles } & \text { R } & \text { Reports: technical, grey } \\ \text { L } & \text { Legislation } & \text { r } & \text { Reports }- \text { open-file } \\ \text { M } & \text { Maps } & \text { S } & \text { Standards/specifications } \\ \text { N } & \text { News items } & \text { T } & \text { Theses } \\ \text { O } & \text { Ongoing research } & \text { V } & \text { Visual media } \\ \text { P } & \text { Pamphlets/posters } & \text { W } & \text { Websites }\end{array}$




\section{Case Study - AESIS}

\section{Provision of AESIS Service}

\section{Instigation}

The genesis and early development of AESIS has been described in a number of papers, for example by Parkin \& Tellis, (1977) and Tellis (1979). These papers draw attention to the hitherto fragmented bibliographic control over Australian geoscience information and the difficulty in locating it. They make mention of the different bodies that at the time generated significant amounts of information, among them the State Geological Surveys, and Mines Departments; the national Bureau of Mineral Resources, Geology and Geophysics (BMR); the mineral research areas of CSIRO; and a number of mining and exploration companies. Many of these enterprises had repositories of their own material, but there was little collaborative effort to share it, and no clearinghouse facility existed.

A compendium of the range of internal databases including bibliographic and numeric, along with collections being constructed up to this period is documented in a geoscience seminar conducted in 1981 (Shelley; Jones in Australian Mineral Foundation, 1981).

In 1970, the Australian Mineral Foundation (AMF) had been established, among other things to launch a resource centre for the mining and petroleum industries, and began to produce printbased current awareness services. It also conducted a national meeting in 1975 at which existing in-house systems of different agencies were discussed, and at which it was accorded a mediating role for a national coordinated scheme.

\section{Database production}

$A E S I S$, produced by AMF, was to report both published and unpublished material. The system was maintained in cooperation with CSIRO, State Departments of Mines and Geological Surveys, NLA, the Australian Geological Survey Organization (AGSO) (formerly the BMR, and at the time of writing known as Geoscience Australia), the Australian Geoscience Information Association, and many companies.

The published material was collected by AMF, which provided document delivery services in support of material identified in literature searches. The unpublished material was reported on standardized datasheets by collaborating institutions. Subject content was to be described using a standardized vocabulary. Data entry was carried out via AMF onto a platform that was provided by the CSIRONET computing network.

\section{Database coverage}

Earth sciences were taken to include the disciplines of geology, geophysics, geochemistry, mining, mineral processing, geomorphology, oceanography, energy, metallurgy, petroleum and natural gas technology, and environmental protection.

Commencing in 1976 AESIS covered published and unpublished documents generated in Australia on the earth sciences in these disciplines. From 1979, coverage was extended to include material dealing with continental Australia published by non-Australian sources.

There were also efforts to include material from prior to 1976, especially for open-file reports (limited distribution documents held in government departments, which could be viewed), and theses, and for material produced by government bodies such as the then BMR, and the State Geological surveys. Retrospective coverage for published material has also been undertaken through special projects for the Geological Society of Australia, Australian Society of Explora- 
tion Geophysicists, Australasian Institute of Mining and Metallurgy, and various Australian Royal Societies. Tabulation of records by year going back to 1907 along with distribution of material by broad categories up to 1980 is given by AMF (Australian Mineral Foundation, 1981)

When production of the database went into abeyance in January 2001 it contained about 200,000 records.

Material scanned for $A E S I S$ was taken from many sources including journals, monographs in series, books, conference papers and proceedings, technical reports, maps, theses, and unpublished and open-file reports. Document backup other than for theses and unpublished material is provided by AMF (Tellis in Lane, 1984). The service did not progress to the point of including digital full text.

\section{Database searching}

The thesaurus used for indexing references to the database has been through several editions firstly as the Australian thesaurus of earth sciences and related terms, but most recently as the Australian geoscience, minerals and petroleum thesaurus. Copies of the Thesaurus have been made available from the AMF in either hardcopy or digital format.

This thesaurus was a product of AMF created independently of the AESIS process, but readily usable for indexing the database.

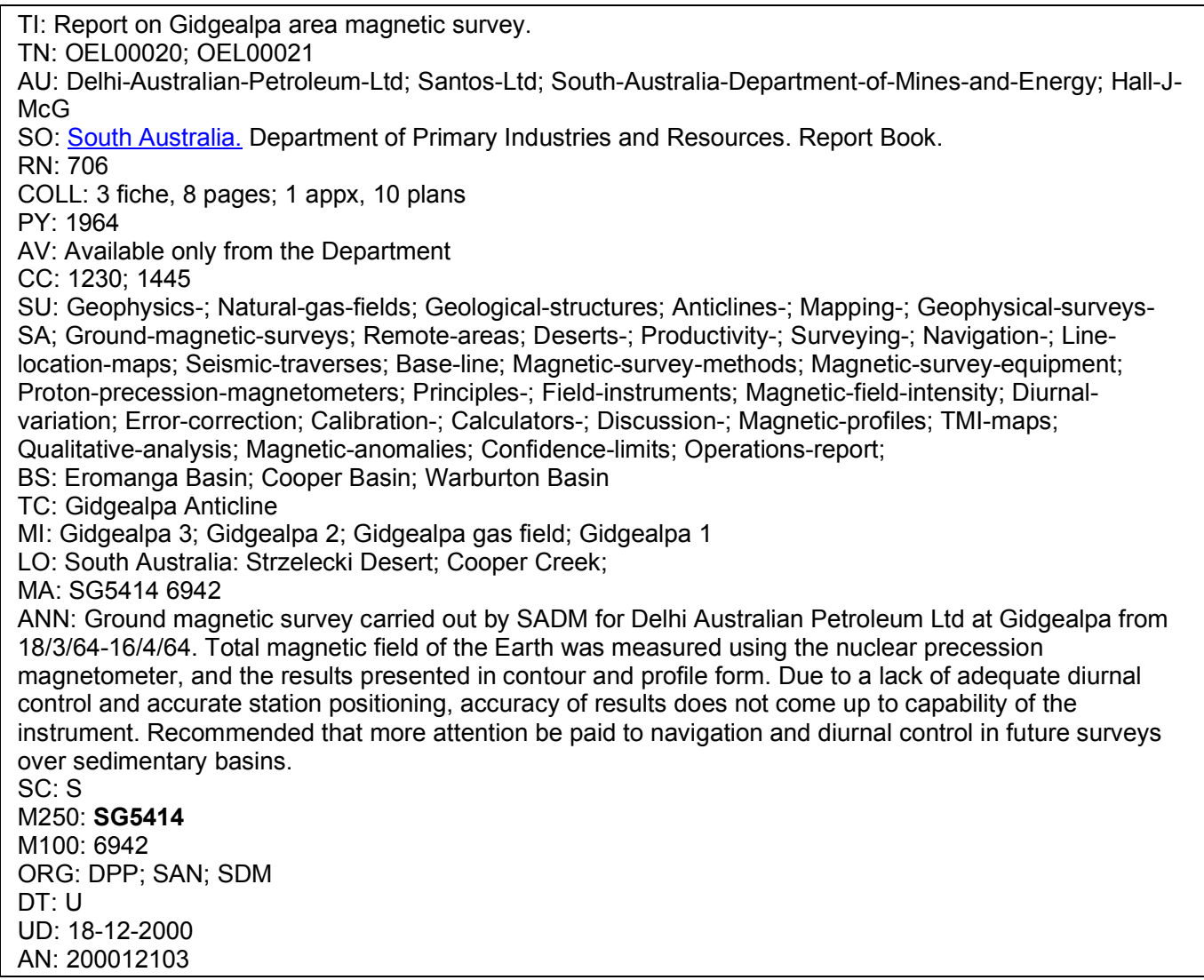

\section{Figure 1: Example of $A E S I S$ record (from Informit)}

The record format, illustrated in Figure 1 is an example of a record as it is formatted for full display from the Informit service. Features of note in the record include: 
- The descriptor field (SU) in which are included terms from the Thesaurus.

- The basin field (BS) which when appropriate, records geological basins - this part of the description was initially held with the descriptors, but as with tectonic units (TC), separate fields have now been created for these terms (existing records were altered to shift the terms into their correct fields).

- The map reference fields (M100, M250) which record codes corresponding to $1: 100,000$ and $1: 250,000$ map sheet areas.

- The availability field (AV) that indicates access to unpublished material.

\section{Information Management Aspects}

This analysis is based upon the protocol outlined earlier under research methodology, and considers in turn, the administrative, analytical and operational aspects.

\section{Administrative information management}

AESIS was coordinated by the AMF in cooperation with the many agencies, referred to previously, and with the principal computer support of CSIRO. Collectively the agencies contributed about $25 \%$ of operating costs. The costs were borne mainly by the petroleum industries through the Australian Geoscience Information Association and many companies (Tellis in Peguero, 1983).

Tellis (1986) writing in general terms about management of databases thought that when goals, objectives and system inputs and outputs had been considered, then the viability of a database needed to take account of:

- Target information: the growing area of information that is useful but not (otherwise) readily accessible.

- Clientele: a relatively large population of users who would use the accessible target information.

- Database: a storage and switching mechanism for linking information to clientele.

- Resources: funding this as well as cooperation from various parties.

- Control and coordination.

He exemplified this approach in the overall functional format of AESIS as shown in Figure 2.

This provided the framework for development milestones as shown in Table 3. Of these, costs at the time were $\mathrm{A} \$ 6,000$ for the survey, $\mathrm{A} \$ 55,000$ for thesaurus development and production of first edition (including thesaurus software development by WRE and AMDEL), and A $\$ 82,000$ systems development (by CSIRO CILES using costs estimated at equivalent bureau and software package costs at the time)

AESIS quarterly was estimated at A $\$ 8,000$ annually for the 500 subscriptions and annual microfiche cumulations at $\mathrm{A} \$ 1,000$ for the same number of subscriptions.

Varying detail of different costings for 1980 is available (Tellis, 1981; 1986). These amount to A $\$ 129,000$ for direct costs with management and support service costs (A $\$ 44,000$ is direct processing costs, $\mathrm{A} \$ 19,000$ is for production cost of products, and $\mathrm{A} \$ 66,000$ management and support services costs of which about $48 \%$ is for purchase of material and about $39 \%$ for salaries of staff). 

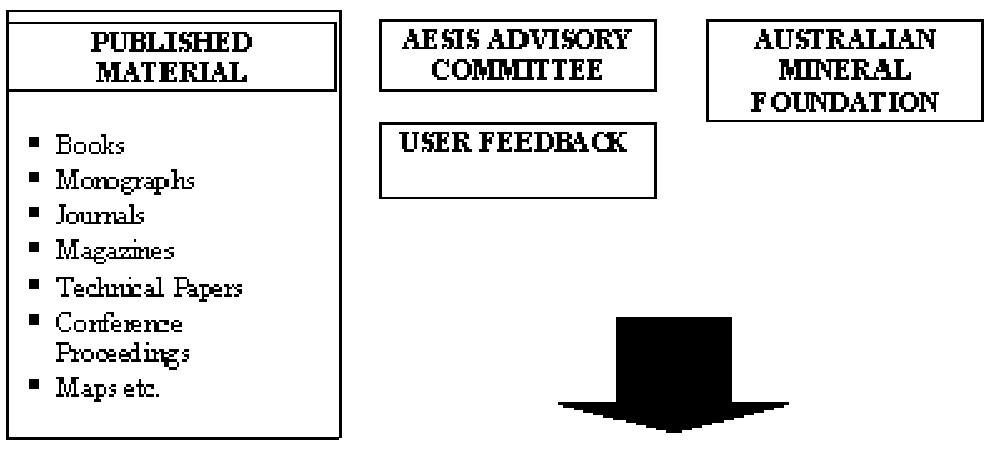

\section{AUSTRALLAN EARTH SCIENCES INF ORMATION \\ SY STEM (AESIS?}

USER FEEDHACK

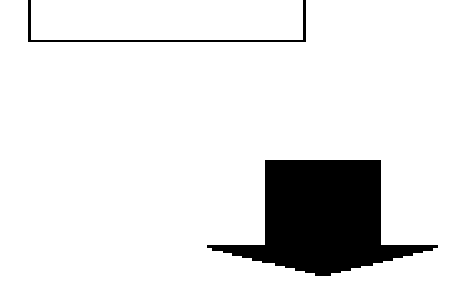

\begin{tabular}{|c|}
\hline $\begin{array}{l}\text { UNPUBEISHED } \\
\text { MATERLAL }\end{array}$ \\
\hline $\begin{array}{l}\text { Received thwoug: } \\
\text { - BMR } \\
\text { - State Geobginal } \\
\text { Sumys } \\
\text { - Uniremites \&CAE' } \\
\text { - Comparies } \\
\text { - Federal \& State } \\
\text { Agencies }\end{array}$ \\
\hline
\end{tabular}

\begin{tabular}{|c|}
\hline $\begin{array}{l}\text { MONIT ORING FOR } \\
\text { IVPUT }\end{array}$ \\
\hline $\begin{array}{l}\text { - CSIRO thoough ASI } \\
\text { - HLA trough AHB } \\
\text { - Special lbraries in } \\
\text { nireral irbutties. }\end{array}$ \\
\hline
\end{tabular}

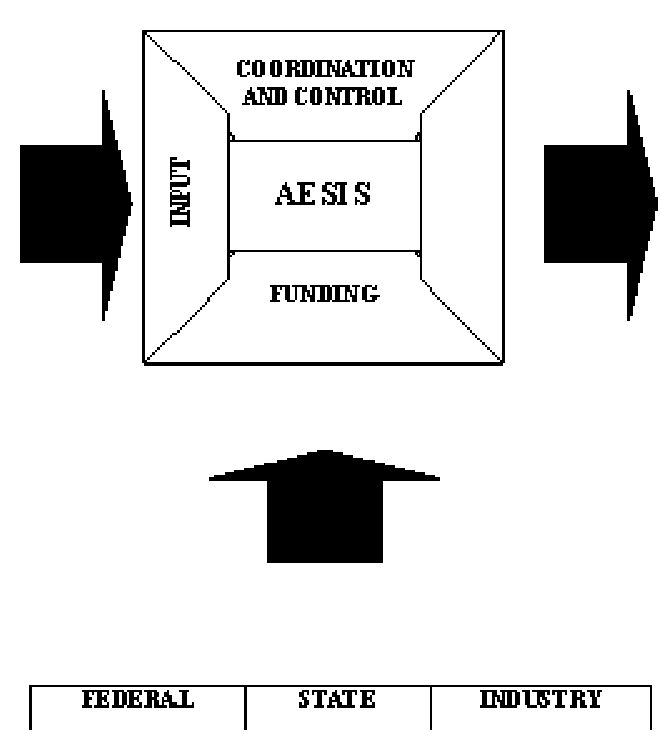

AESIS Onartry with all intex:

AESIS onmlation on

COM re-sorted in main anthor sequerce, with all inderes

State Quarterly list for state sirns

Spenil list with slf contained inderes

Retrospective searches or lineb atch mode

Figure 2: AESIS overall functional format (from Lavo, 1981, p. 25)

An extended figure of $\mathrm{A} \$ 158,000$ per annum is derived by including a fifth of the total development cost (assuming amortization over a five year period). On this basis of this maximum figure, a unit cost of $A \$ 42.7$ is derived for each of the 3700 records produced by the two services during the period. A unit cost figure of about A $\$ 20$ corresponds with actual processing and is commensurate with that of figures reported by other services at the time

These attempts to quantify processing costs, and willingness to share them publicly were a valuable lead for other database developers embarking upon similar ventures at the time. What such figures could not do however, was to value the accumulated information. This is particularly poignant in view of the subsequent demise of AMF for financial reasons.

AMF ceased operations at the end of 2001 because of the drastic decline in the number of companies and professionals within the mining industry. It became un-economic for it to continue to operate, however attempts have been made to support key operations such as AESIS via other avenues.

In April 2002, Chief Government Geologists from federal and state authorities had been unable to agree on a funding model to support continued AESIS production. However Geoscience Australia subsequently has entered an arrangement with the American Geological Institute to produce in- 
dexed material in association with Australian state agencies. Inclusion of records in AGI's Georef database began in November 2003. Therefore a path has been followed similar to other services that have provided input as part of an international approach.

\section{Table 3: AESIS milestones (Tellis, 1979)}

\begin{tabular}{|c|c|}
\hline 1. 1972: & $\begin{array}{l}\text { AMF Australia-wide information services survey conducted to ascertain industry needs along with de- } \\
\text { gree of participation to be expected from government academic and industry sources. }\end{array}$ \\
\hline 2. 1973: & $\begin{array}{l}\text { ERISAT commenced as manually produced monthly current awareness bulletin that provided an ex- } \\
\text { perimental system for thesaurus development and } A E S I S \text { to follow. }\end{array}$ \\
\hline 3. 1974: & The development of the thesaurus an indexing vocabulary for the geosciences in Australia. \\
\hline 4. 1975: & $\begin{array}{l}\text { the first geosciences information seminar held at AMF that gave a mandate for the creation of the earth } \\
\text { sciences bibliographic database. }\end{array}$ \\
\hline 5. 1976: & $\begin{array}{l}\text { Production of first working edition of Australian thesaurus of earth sciences and related terms; pilot } \\
\text { study and development of } A E S I S \text { with some sample products on CSIRONET. }\end{array}$ \\
\hline 6. 1978 & $\begin{array}{l}\text { Stabilization of AESIS products and production routines for AESIS quarterly, AESIS cumulation on mi- } \\
\text { crofiche, AESIS special lists, and retrospective search output forms }\end{array}$ \\
\hline 7. 1979 & Computer typesetting and production of second thesaurus edition in hard copy \\
\hline 8. 1980 & $\begin{array}{l}\text { Transfer of ESRISAT from manual production to computer typesetting in same form as AESIS quarterly } \\
\text { with new ERISAT six-monthly cumulation for international material; mounting of AESIS on Ausinet for } \\
\text { interactive public use }\end{array}$ \\
\hline
\end{tabular}

\section{Analytical information management}

For AESIS the principal analytical aspects to be considered are the determination of user needs, the identification of appropriate material for inclusion, and the evaluation of performance of the system.

A 1972 survey (Dixon \& Tellis, 1972) was the major analysis of anticipated user needs for the service. However although this survey sought information on individual user needs within organizations detailed in an appendix, the document confined itself to reporting institutional coverage and current information provision along with recommendations concerning an agency to handle an STI service.

Subsequently, AMF strived to be comprehensive within the subject areas delineated. The difficulties presented in being so inclusive included fugitive material such as papers presented at regional seminars hosted by discipline areas outside the core. They endeavored to identify such material from accession lists, current awareness bulletins and publishers blurbs. An arrangement with NLA to make use of received deposit copies petered out. No systematic input of theses was achieved despite a suggestion for 'data transmission sheets' to be submitted by universities. Nevertheless 860 theses were included in the database by October 1983 (Tellis in Lane, 1984). There are now many thousands.

There was also a project to include open-file company exploration reports and theses for the period 1965-75 sponsored by the Australian Mineral Industries Research Association and thirteen companies.

Performance evaluation carried out included the use of an evaluative framework set up in a study by Pruett on the international Georef database (Tellis, 1986). This was used with reference to $A E S I S$ to deduce among other things:

- Subject coverage was wider than other geoscience databases. 
- Currency was markedly higher than other geoscience services.

- Thesis coverage was not as comprehensive as desirable.

- There was a low incidence of duplicate records.

- Document type tags enabled isolation of proceedings, chapters, etc if required.

- Over $40 \%$ of citations were to open-file and unpublished survey reports.

- Indexing provided for distinction between processes (e.g. ' 'faulting'), and occurrences (e.g. 'faults'); however the collaborative nature of indexing, may lead to inconsistencies in this respect, which may be addressed by training, or global corrections for the database.

- Map sheet references provided for searching by grid references.

- Formal training programs were still to be initiated.

Tellis (in Judge \& Gerrie, 1986) also examined performance in terms of cost effectiveness and benefit. He commented upon the difficulty of assessing effectiveness without recourse to data from comparable systems, though finding through discussion with colleagues that unit costs are comparable. He made particular reference to trade-offs such as distributed collaborative indexing, and other cooperative procedures.

By contrast, cost benefit (with orientation towards user impressions) was examined in more detail. For example, he cited earlier measures of the number of journals that a user would have to scan if a current awareness bulletin were unavailable, and applied them to the AESIS service which itself was found to exhibit a Bradford distribution whereby in this case $70 \%$ of the reported papers are covered by 37 periodicals.

Beginning with estimates of the cost to a company of a professional's time, and taking into account salaries and scanning times that would be necessary to look at the same literature if the service had not been available, he was able to tabulate significant benefits in dollar terms by subtracting processing costs from estimated scanning costs.

\section{Operational information management}

Initially, the database was created on CSIRONET by dispatch of coding forms to CSIRO from AMF for paper tape data entry. Later data entry took place directly from AMF, and from 1982 this was managed through a host DEC PDP11/44 minicomputer for validation, then storage on a Cyber76 on CSIRONET in Canberra. The thesaurus was transferred to the PDP host (Tellis in Peguero, 1983).

Software support was provided by the CILES System Development Group. The live database was updated monthly on CSIRONET. From 1980, quarterly updates were also produced for Ausinet where they were mounted after conversion to STAIRS with software developed by ACI Computer Services. Full document backup (or referral for unpublished documents) was provided by AMF.

In 1987 AESIS was relocated from CSIRONET to CLIRS as part of its Australian Resources Industry Database concept.

Other operational aspects concerned the continuing maintenance of the thesaurus terminology and production of new editions, as well as the production of other titles that were structured along the same lines as AESIS. For example, Earth Science and Related Information Selected Annotated Titles (ESRISAT) selectively covered earth sciences serial publications received by the AMF and South Australian Department of Mines and Energy libraries and State Library of South Australia 
(Tellis in Peguero, 1983). Seven indexes: subject, locality, author, map sheet, mine/deposit/well/name, stratigraphic and serial title, were created for the monthly service which also had semi-annual cumulations. These were the same indexes as for AESIS, and the material included incorporated AESIS updates along with library acquisitions.

Document delivery costs estimated at $\$ 5$ per request excluding requester's cost for normal (comparing with quoted national figures of $\$ 5.56$ and lending of $\$ 3.72$ ) although $90 \%$ are about $\$ 3.60$ are close to the national figure and $10 \%$ are about $4-5$ times that.

\section{Conclusion}

There were concerted efforts to develop STI services in Australia during the 1960s and 70s within a public information policy framework. However, although these efforts led to greater awareness of the issues, national development lacked a strategy that stakeholders could follow to avoid gaps in service and duplication. This situation was exacerbated by funding constraints. However, a rapidly developing computing and communications environment coupled with the efforts of some visionaries working independently in different agencies, saw to it that the country was comparatively well-serviced using a combination of international and local services.

One of the agencies in the vanguard was the AMF, whose AESIS service provides the focus for the case study. The initial success of AESIS can, in no small part, be attributed to the acuity of its management, and it provided an prototype for similar Australian services. Despite the demise of its harboring organization, the quality of the database has seen it revived in a different context for the petroleum and exploration industry. However, its continuation will happen effectively only by application of the collaborative principles that contributed to is original success.

This case study approach aspires to test whether a particular service is carried out according to the tenets of a domain-based understanding of information management. This requires attention to be paid to planning and strategy through administrative, analytical and operational aspects. Administrative aspects may have to take into account public policy, and analytical aspects include user needs and systems analysis. The AMF was found to be conscious of the need for consideration of each of these domains, though the elements of the domains were not articulated as such by the enterprise itself at the time of development.

The three domains have proved in be useful in this case for conceptualizing an application of information management. They represent an approach by Middleton (2002) that endeavors to illustrate how information management reconciles information science principles. Therefore if such understanding can be applied in similar cases, it should prove useful for the planning and development of services. This study is limited by focusing on a single case, by limited recourse to historical records, and by examining the service at a time when it was no longer operational in the same way as during the period under consideration. However, subsequent case analysis of similar STI services is showing promise in confirming the analytical framework.

Whether the analysis can be extended to information services in general is problematical. However it seems to provide a useful understanding at least in this constrained area, of those factors that need to be addressed to make such a service work well according to tenets of the field.

\section{Acknowledgements}

My great appreciation is extended to Des Tellis for his input to and comments upon the AESIS material. My thanks also to anonymous referees for their constructive comments on the content and emphasis of this work 


\section{References}

Abbott, A. D. (1988). The system of professions: An essay on the division of expert labor. Chicago, Il, USA: University of Chicago Press.

Australia Scientific and Technological Information Services Enquiry Committee. (1973-5). The STISEC report : report to the Council of the National Library of Australia by the Scientific and Technological Information Services Enquiry Committee, May 1973. Volume 1: Scientific and technological information services in Australia; Volume 2: Procedures, evidence examined, findings and appendixes. Canberra, ACT, Australia: National Library of Australia.

Australian Mineral Foundation. (1981). Seminar: geoscience numeric and bibliographic data: papers and recommendations. Adelaide, SA, Australia: AMF.

Corcoran, M., Dagar, L., \& Stratigos, A. (2000). The changing roles of information professionals. Online, 24 (2), 28-33.

Cronin, B., Stiffler, M., \& Day, D. A. (1993). The emergent market for information professionals: Educational opportunities and implications. Library Trends, 42 (3), 257-276.

Debons, A., King, D. W., Mansfield, U., \& Shirey, D. L. (1981). The information professional: Survey of an emerging field. NY: Marcel Dekker.

Diener, R. A. V. (1992). Strategic, analytic and operational domains of information management. Bulletin of the American Society for Information Science, 19 (1), 18-19.

Dixon, P., \& Tellis, D. A. (1972). AMF information services survey (AMDEL Report; no. 911). Adelaide, SA, Australia: Australian Mineral Development Laboratories.

Ellis, D., Allen, D., \& Wilson, T. (1999). Information science and information systems: Conjunct subjects disjunct disciplines. Journal of the American Society for Information Science, 50 (12), 1095-1107.

Griffiths, J.-M. (2000). Back to the future: information science for the new millennium. Bulletin of the American Society for Information Science, 26 (4), 24-27.

Judge, P., \& Gerrie, B. (Eds.). (1986). Small scale bibliographic databases. Sydney, NSW, Australia: Academic.

Khazanchi, D., \& Munkvold, B. E. (2000). Is information systems a science? An inquiry into the nature of the information systems discipline. Database for Advances in Information Systems, 31 (3), 24-42.

Lane, L. (Ed.). (1984). Engineering information and documentation in Australia: Problems and solutions. Proceedings of a national seminar conducted by Footscray Institute of Technology, 25 November 1983. Footscray, VIC, Australia: Footscray Institute of Technology.

Lavo, B., comp. (1981). Resource sharing: A necessity for the '80s. Seminar organised by NZLA Special Libraries Section; LAA Special Libraries Section; LAA Information Science Section; Christchurch New Zealand, 1981. Wellington, New Zealand: New Zealand Educational Institute.

Maguire, C., Weir, T., \& Wood, L. (1987). Scientific and technological information: Its use and supply in Australia. Canberra, ACT, Australia: Department of Science Scientific Development Division.

Middleton, M. (2002). Information management: A consolidation of operations, analysis and strategy. Wagga Wagga, NSW, Australia: CSU Centre for Information Studies.

Middleton, M. (2004). Drops in the ocean: The development of scientific and technological information services in Australia. In W. B. Rayward \& M. E. Bowden (Eds.), The history and heritage of scientific and technological information systems (pp. 353-360). Medford, NJ, USA: Information Today for American Society for Information Science and Technology and Chemical Heritage Foundation. (Also available from http://www.chemheritage.org/events/event-asist2002.html)

National Library of Australia. (1977). Towards an Australian industry information network. Canberra, ACT, Australia: NLA. 
Norton, M. J. (2000). Introductory concepts in information science. Medford, NJ, USA: Information Today for ASIS.

Parkin, L. W., \& Tellis, D. A. (1977). Australian Earth Sciences Information System. Proceedings of the Australasian Institute of Mining and Metallurgy (262), 7-23.

Peguero, G. (Ed.). (1983). Australian clearing houses and data bases: Towards a national policy. Proceedings of a national seminar conducted at Footscray Institute of Technology, 19 November 1982. Footscray, Australia: Footscray Institute of Technology Library.

Quinn, S. (Ed.). (1988). Directory of Australian and New Zealand databases (3rd ed.). Hawthorn, VIC, Australia: Australian Database Development Association.

Rowley, J. (1998). Towards a framework for information management. International Journal of Information Management, 18 (5), 359-369.

Rowley, J. (1999). In pursuit of the discipline of information management. New Review of Information and Library Research, 5, 65-77.

Saracevic, T. (Ed.). (1970). Introduction to information science. NY: Bowker.

Tellis, D. A. (1979). The Australian Earth Sciences Information System (AESIS): A co-operative national venture. Australian Special Libraries News, 12 (March), 37-43.

Tellis, D. A. (1981). Australia-wide information services for the mineral and petroleum industries: Cost aspects, Combined conference of the Library Association of Australia and New Zealand Library Association (pp. 254-270). Sydney, NSW, Australia: Library Association of Australia.

Tellis, D. A. (1986). Earth sciences databases: Observations on information associated with a globally sensitive resource. Information Online, 86. Proceedings of the First Australian Online Information Conference, Sydney, 20 - 22 January 1986 (pp. 118-129). Sydney, NSW, Australia: Library Association of Australia.

Webber, S. (2003). Information science in 2003: A critique. Journal of Information Science, 29 (4), 311 329.

Wilson, T. D. (2003). Information management. In J. Feather \& R. P. Sturges (Eds.), International encyclopedia of information and library science (2nd ed., pp. 263-277). London: Routledge.

Yin, R. K. (2003). Case study research: Design and methods (3rd ed.). Thousand Oaks, CA, USA: SAGE Publications.

\section{Biography}

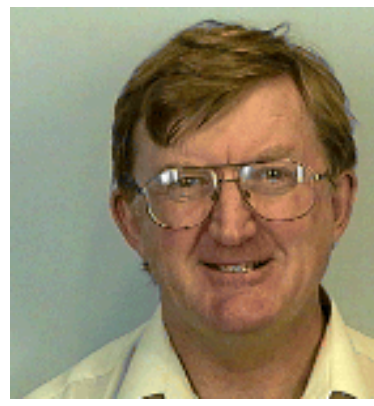

Michael Middleton is a senior lecturer in the School of Information Systems at Queensland University of Technology. His areas of research and scholarship are information management, information use analysis, and library systems, and he has made numerous presentations and published extensively in these areas. Recent publications include the books Information Management, and with Len Asprey, Integrative document and content management. Detail on these and other publications are available at his personal website http://sky.fit.qut.edu.au/ middletm/ 